\title{
Perbandingan Koefisien Kekuatan Relatif dan Umur Rencana Perkerasan Jalan Lapis Aus (AC-WC) menggunakan BNA Blend 75/25 dan Aspal Pen 60/70
}

\author{
Barkah Wahyu Widianto \\ Program Studi Teknik Sipil, Institut Teknologi Nasional (Itenas) - Bandung \\ Email: barkah@itenas.ac.id
}

\begin{abstract}
ABSTRAK
BNA Blend 75/25 merupakan jenis aspal modifikasi baru di Indonesia. Sampai saat ini, penggunaan BNA tersebut belum banyak dilaksanakan pada pekerjaan jalan di Indonesia. Jalan Alternatif Nagreg Jawa Barat merupakan proyek pertama jalan nasional yang menggunakan BNA Blend pada lapisan perkerasannya. Penelitian ini bertujuan untuk membandingkan kinerja perkerasan jalan menggunakan BNA Blend 75/25 dengan Aspal Konvensional (Pen 60/70) dari aspek koefisien kekuatan relatif (a) campuran beraspal dan Umur Rencana berdasarkan analisis struktur perkerasan Metode Bina Marga. Uji laboratorium dilakukan untuk mengetahui karakteristik aspal, agregat dan campuran beraspal dengan keluaran berupa nilai Modulus Resillient yang selanjutnya digunakan untuk mendapatkan nilai a dan Umur Rencana. Perkerasan jalan yang menggunakan BNA Blend 75/25 menghasilkan nilai a 3,7 \% lebih besar dan Umur Rencana 1 tahun lebih lama dibandingkan dengan aspal Pen 60/70.
\end{abstract}

Kata kunci: koefisien kekuatan relatif, Umur Rencana, BNA Blend 75/25.

\begin{abstract}
BNA Blend 75/25 is a new type of asphalt modification in Indonesia. Until recently, the use of BNA Blend 75/25 has not been widely implemented on road construction in Indonesia. Alternatif Road, Nagreg - West Java was the first national road project which applied the BNA Blend to the pavement layer. This research aimed to compare the performance of pavement using the BNA Blend 75/25 to the conventional asphalt (Pen 60/70). Coefficient of relative strength (a), and design life were generated as a result of pavement structural analysis based on Bina Marga method. For this purpose, laboratory tests were conducted to determine the characteristics of aggregates, both types of asphalts and asphalt mixtures with the output of resillient modulus value. Furthermore, the modulus value was used to calculate the a-value and design life of each type of asphalt. Pavement with BNA blend produced a-value and design life 3.7\% higher, and one-year longer than pavement with asphalt Pen 60/70, respectively.
\end{abstract}

Keywords: coefficient of relative strength, design life, BNA Blend 75/25 


\section{PENDAHULUAN}

Secara umum, banyak permasalahan dalam perkerasan jalan di Indonesia, seperti pengaruh temperatur udara yang tinggi, intensitas curah hujan berkala yang besar, dan beban lalu-lintas yang berlebihan (overloading) yang menjadi penyebab utama terjadinya keruntuhan dini jalan. Selama masa layan, akibat pengaruh cuaca, sifat bahan pengikat misalnya indeks penetrasi aspal yang merupakan parameter untuk mengetahui ketahanan terhadap temperatur di dalam campuran akan berubah. Di Indonesia telah memiliki produk aspal modifikasi asbuton, yaitu BNA Blend 75/25, hasil pencampuran antara aspal minyak Pertamina Pen 60/70 sebesar 75\% dan BNA 25\%. Selain kualitasnya yang tinggi dan harga yang lebih kompetitif, aplikasinya telah digunakan untuk perkerasan jalan dengan lalu lintas berat di Indonesia.

Adapun salah satu jalan di Indonesia yang menggunakan aspal modifikasi BNA Blend 75/25 adalah jalan alternatif Nagreg dengan panjang 4,60 km dari panjang keseluruhan 5,26 km yang diperkeras dengan campuran beraspal Asphalt Concrete (AC) pada lapisan Wearing Coarse (WC). Penelitian ini mengkaji pengaruh penggunaan BNA Blend 75/25 dan Aspal Pen 60/70 di perkerasan jalan tersebut dengan pengujian di laboratorium. Kemudian dilakukan uji lanjut UMMATA untuk mendapatkan nilai modulus kekakuan dan koefisien relatif ( $a$ ) untuk menilai struktur perkerasan jalan. Faktor beban lalu lintas dan pengaruh modulus kekakuan campuran beraspal terhadap durabilitas perkerasan jalan akan mempengaruhi sistem pemeliharaan selama umur rencana, sehingga pada akhirnya terlihat perbedaan Umur Rencana perkerasan jalan yang menggunakan BNA Blend 75/25 dan aspal Shell PEN 60/70.

\section{METODOLOGI}

Dalam penelitian ini, umur rencana perkerasan jalan dianalisis dengan tahapan metodologi seperti pada

\section{Gambar 1.}

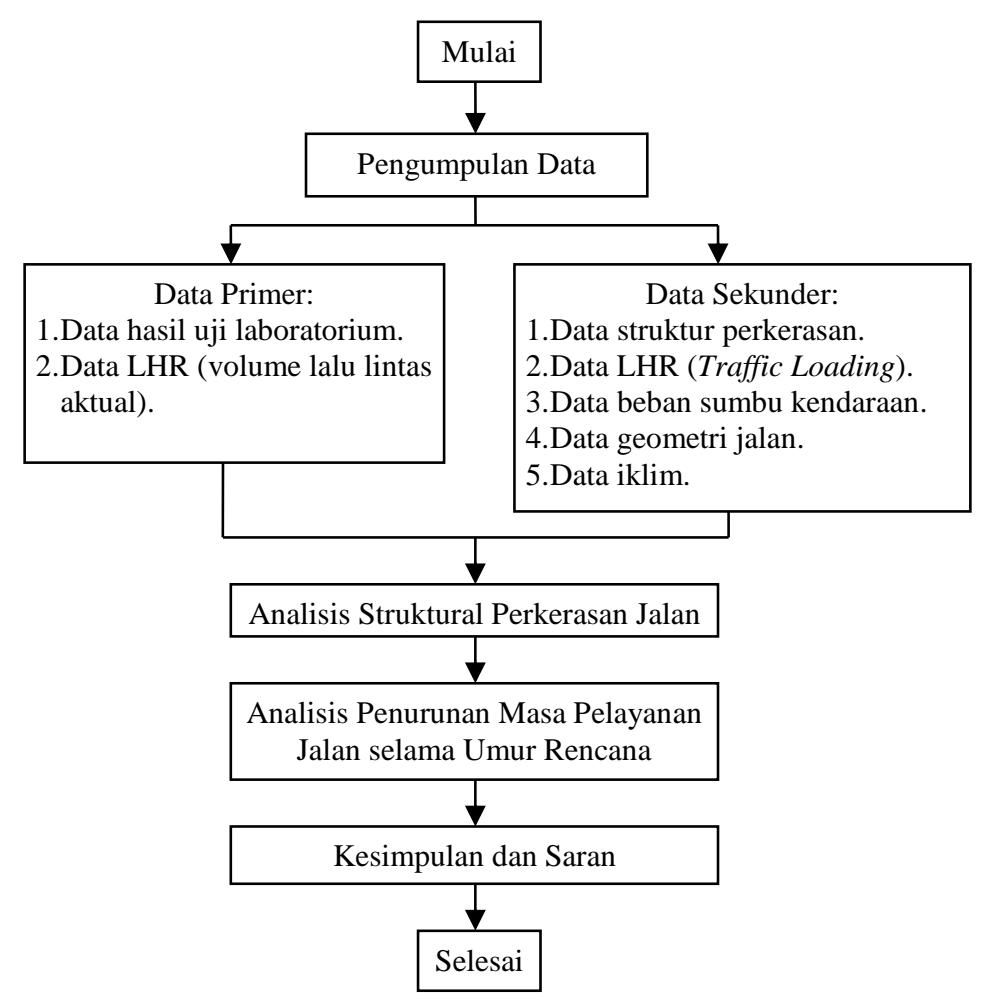

Gambar 1. Metodologi Penelitian 
Penelitian ini dititikberatkan pada pengujian laboratorium, analisis struktur perkerasan, dan Umur Rencana analisis. Langkah pertama dilakukan dengan tahap pengumpulan data, yaitu data primer dan sekunder. Karena dalam penelitian ini membandingkan perkerasan jalan yang menggunakan BNA Blend 75/25 dengan perkerasan jalan tersebut, jika menggunakan aspal PEN 60/70, maka dilakukan uji laboratorium untuk mendapatkan data modulus kekakuan dari campuran beraspal, seperti uji karakteristik agregat, aspal, uji Marshall dan Kepadatan Mutlak, pengujian modulus Resilen dengan UMATTA. Adapun data yang dibutuhkan adalah Job Mix Formula (JMF) campuran beraspal jalan alternatif Nagreg yang diperoleh dari PT. Aston Adhi Jaya sebagai pembanding JMF yang dilakukan di laboratorium. Kemudian data Lalu Lintas Harian Rata-rata (LHR) untuk tahun 2012 diperoleh dengan melakukan survey primer Traffic Counting di ruas jalan alternatif Nagreg selama 24 jam yang dilakukan di hari biasa. Data ini nantinya digunakan untuk menghitung beban kendaraan yang mempengaruhi masa pelayanan jalan selama umur rencana dan juga sebagai data dasar LHR untuk memprediksi lalu lintas di tahun-tahun berikutnya.

Data sekunder yang dikumpulkan adalah data struktur perkerasan berupa hasil coredrill, data LHR dan Traffic Loading berupa historis data LHR tahun 2008 sampai 2011 serta berat beban sumbu standar kendaraan, data environment (lingkungan) berupa geometrik jalan untuk mengetahui kelandaian dan lebar jalan, serta iklim (curah hujan dan temperatur), data maintenance yang digunakan untuk menjadi referensi atau acuan pemeliharaan jalan dan untuk membandingkan rencana data pemeliharaan yang ada dengan data pemeliharaan hasil analisis.

Data-data yang diperoleh dari tahap pengumpulan data diproses untuk analisis struktural perkerasan jalan yang dipengaruhi modulus kekakuan campuran lapis aus (AC-WC) yang menggunakan aspal yang berbeda (BNA Blend 75/25 dan aspal PEN 60/70). Proses ini kemudian dianalisis dan disesuaikan dengan kebutuhan data. Dari analisis struktural perkerasan jalan ini akan dapat diketahui besarnya tingkat penurunan masa pelayanan jalan di beberapa tahun kedepan sampai jalan tersebut dapat dikatakan kritis. Salah satu yang mempengaruhi penurunan masa pelayanan ini adalah beban kendaraan yang terus meningkat disetiap tahunnya. Sehingga diperoleh umur rencana perkerasan jalan berupa kinerja perkerasan atau penurunan masa pelayanan jalan.

\section{HASIL DAN PEMBAHASAN}

\subsection{Hasil Analisis Pengujian Laboratorium}

Aspal yang digunakan dalam penelitian ini adalah aspal BNA Blend 75/25 dan dibandingkan dengan menggunakan aspal PEN 60/70. Karakteristik kedua aspal ini kemudian dibandingkan terhadap persyaratan spesifikasi aspal modifikasi asbuton yang diproses dan aspal Pen 60/70. Hasil dari pengujian karakteristik kedua aspal ini disajikan pada Tabel 1 [4].

Tabel 1. Hasil Pengujian Karakteristik Aspal BNA Blend 75/25 dan Aspal PEN 60/70 [3], [4]

\begin{tabular}{llccccc}
\hline \multirow{2}{*}{ No } & \multirow{2}{*}{ Jenis Pengujian } & Metode & BNA Blend 75/25 & \multicolumn{2}{c}{ Shell 60/70 } \\
\cline { 3 - 7 } & & & Hasil Uji & Spek & Hasil Uji & Spek \\
\hline 1 & Penetrasi $@ 25^{\circ} \mathrm{C}, \mathrm{dmm}$ & SNI 06-2456-1991 & 54,9 & $40-55$ & 66,3 & $60-70$ \\
\hline 2 & Titik lembek $\left[{ }^{\circ} \mathrm{C}\right]$ & SNI 06-2434-1991 & 53 & - & 50 & $\geq 48$ \\
\hline 3 & Indeks penetrasi & & $-0,25$ & $\geq-0,5$ & $-0,51$ & $\geq-1,0$ \\
\hline 4 & Daktilitas $@ 25^{\circ} \mathrm{C}$ & SNI 06-2432-1991 & $\geq 100$ & $\geq 100$ & $>100$ & $\geq 100$ \\
\hline 5 & Kadar bitumen $\%$, kelarutan & SNI 06-2432-1991 & $90,48 \%$ & $\geq 90$ & $99,63 \%$ & $\geq 99$ \\
\hline 6 & Titik nyala $\left[{ }^{\circ} \mathrm{C}\right]$ & SNI 06-2433-1991 & 308 & $\geq 232$ & 339,5 & $\geq 232$ \\
\hline 7 & Berat jenis $\left[\mathrm{gr} / \mathrm{cm}^{3}\right]$ & SNI 06-2441-1991 & 1,09 & $\geq 1$ & 1,04 & $\geq 1$ \\
\hline 8 & Kehilangan berat TFOT [\%] & SNI 06-2440-1991 & $0,20 \%$ & $\leq 0,8$ & $0,30 \%$ & $\leq 0,8$ \\
\hline 9 & Penetrasi setelah TFOT [\%] & SNI 06-2456-1991 & 54,2 & $\geq 54$ & 55,3 & $\geq 54$ \\
\hline 10 & Indeks penetrasi setelah & & 0,23 & $\geq 0,0$ & $-0,48$ & $\geq-1,0$ \\
\hline
\end{tabular}


Tabel 1. Hasil Pengujian Karakteristik Aspal BNA Blend 75/25 dan Aspal PEN 60/70 [4], [7] (lanjutan)

\begin{tabular}{|c|c|c|c|c|c|c|}
\hline \multirow{2}{*}{ No } & \multirow{2}{*}{ Jenis Pengujian } & \multirow{2}{*}{ Metode } & \multicolumn{2}{|c|}{ BNA Blend 75/25 } & \multicolumn{2}{|c|}{ Shell 60/70 } \\
\hline & & & Hasil Uji & Spek & Hasil Uji & Spek \\
\hline 11 & Daktilitas setelah TFOT [\%] & SNI 06-2434-1991 & 68,5 & $\geq 50$ & $>100$ & $\geq 100$ \\
\hline 12 & $\begin{array}{l}\text { Viskositas pada suhu } 135^{\circ} \mathrm{C} \text {, } \\
\text { Cst }\end{array}$ & SNI 06-6721-1991 & 728,5 & $385-2000$ & 476,25 & $\geq 385$ \\
\hline 13 & $\begin{array}{l}\text { Temperatur campuran }\left[{ }^{\circ} \mathrm{C}\right] \\
\text { (Viskositas } 170 \mathrm{Cst})\end{array}$ & & 176 & & 156 & \\
\hline 14 & $\begin{array}{l}\text { Temperatur pemadatan }\left[{ }^{\circ} \mathrm{C}\right] \\
\text { (Viskositas } 280 \mathrm{Cst} \text { ) }\end{array}$ & & 162 & & 146 & \\
\hline
\end{tabular}

Hasil pengujian viskositas didapatkan temperatur pencampuran dan temperatur pemadatan pada masingmasing variasi campuran aspal. Pada percobaan viskositas didapat suhu pencampuran dan pemadatan aspal BNA Blend $75 / 25$ lebih tinggi daripada aspal PEN 60/70, yaitu sebesar $176^{\circ} \mathrm{C}$ dan $162^{\circ} \mathrm{C}$ pada aspal BNA Blend $75 / 25$ dan $156^{\circ} \mathrm{C}$ dan $146^{\circ} \mathrm{C}$ pada aspal PEN $60 / 70$. Hal ini disebabkan aspal BNA Blend 75/25 lebih keras daripada aspal PEN 60/70, sehingga diperlukan suhu yang cukup tinggi untuk pencampuran dan pemadatannya. Hasil pengujian sifat fisik terhadap agregat dihasilkan bahwa agregat memenuhi persyaratan yang ditentukan dalam spesifikasi sehingga layak digunakan dalam perkerasan jalan dan identik dengan agregat yang digunakan di jalan alternatif Nagreg.

Untuk melihat karakteristik campuran beraspal maka dilakukan pengujian Nilai Kadar Aspal Optimum (KAO) yang diperoleh melalui pengujian dengan metode Marshall dan dilengkapi dengan metoda Kepadatan Mutlak (Ditjen Bina Marga, Kementerian Pekerjaan Umum, 2010). Perbandingan tersebut disajikan dalam Tabel 2. Adapun untuk pengujian perendaman Marshall yang merupakan pengujian untuk mengetahui durabilitas campuran beraspal dapat dilihat pada Tabel 3 [3], [4].

Tabel 2. Hasil Pengujian Karakteristik Aspal BNA Blend 75/25 dan Aspal PEN 60/70 [3], [4]

\begin{tabular}{lcccc}
\hline \multirow{2}{*}{ Sifat-sifat Campuran } & \multicolumn{2}{c}{ Aspal Shell 60/70 } & \multicolumn{2}{c}{ Aspal BNA Blend 75/25 } \\
\cline { 2 - 5 } & $\mathbf{A}_{\mathbf{1}}[4]$ & Spesifikasi [3] & $\mathbf{A}_{\mathbf{2}}$ [4] & Spesifikasi [3] \\
\hline KAO PRD [\%] & 6,30 & - & 6,15 & - \\
\hline Berat Isi [t/m ${ }^{3}$ ] & 2,310 & - & 2,324 & - \\
\hline V I M Marshall [\%] & 4,30 & - & 4,90 & - \\
\hline V I M Refusal [\%] & 3,60 & $>2,5$ & 3,55 & $>2,5$ \\
\hline V M A [\%] & 16,05 & $>15$ & 15,80 & $>15$ \\
\hline V F A [\%] & 75,10 & $>65$ & 72,00 & $>65$ \\
\hline Stabilitas [kg] & 1.010 & $>800$ & 1.495 & $>1.000$ \\
\hline Kelelehan [mm] & 3,70 & $>3$ & 3,50 & $>3$ \\
\hline $\begin{array}{l}\text { Marshall Quotient (MQ) } \\
\text { [kg/mm] }\end{array}$ & 273 & $>250$ & 390 & $>300$ \\
\hline
\end{tabular}

Tabel 3. Hasil Analisis Perendaman Marshall pada KAO Refusal [3], [4]

\begin{tabular}{lcccc}
\hline \multirow{2}{*}{ Sifat-sifat Campuran } & \multicolumn{2}{c}{ Aspal Shell 60/70 } & \multicolumn{2}{c}{ Aspal BNA Blend 75/25 } \\
\cline { 2 - 5 } & $\mathbf{A}_{\mathbf{1}}[\mathbf{4}]$ & Spesifikasi [3] & $\mathbf{A}_{\mathbf{2}}[4]$ & Spesifikasi [3] \\
\hline Kadar aspal [\%] & 6,30 & - & 6,15 & \\
\hline Stabilitas perendaman $24 \mathrm{jam}\left(S_{2}\right)[\mathrm{kg}]$ & 975 & & 1.458 & - \\
\hline Stabilitas awal $\left(S_{1}\right)[\mathrm{kg}]$ & 1.010 & $\geq 800$ & 1.490 & $\geq 1.000$ \\
\hline Indeks Kekuatan Sisa $(\mathrm{IKS})\left(S_{2} / S_{1}\right)[\%]$ & 95,04 & $>90$ & 97,60 & $>90$ \\
\hline
\end{tabular}


Pengujian modulus Resilien (MR) dilakukan dengan menggunakan alat UMATTA, yaitu menggunakan benda uji diametral seperti benda uji Marshall dan dibuat pada Kadar Aspal Optimum (KAO ${ }_{\text {PRD }}$ ). Pengujian mengacu kepada ASTM D 4123-82 (1987), temperatur yang dipakai pada pengujian yaitu $25^{\circ} \mathrm{C}$ dan $45^{\circ} \mathrm{C}$. Hasil pengujian untuk kedua jenis campuran tersebut dapat dilihat pada Tabel 4 [4].

Tabel 4. Nilai Modulus Resilien Hasil Pengujian UMATTA [4]

\begin{tabular}{lccc}
\hline \multicolumn{1}{c}{$\begin{array}{c}\text { Jenis } \\
\text { Campuran }\end{array}$} & $\begin{array}{c}\text { KAO } \\
{[\%]}\end{array}$ & $\begin{array}{c}\text { Temperatur } \\
\text { Benda Uji }\left[{ }^{\circ} \mathbf{C}\right]\end{array}$ & $\begin{array}{c}\text { Modulus Resillien } \\
{[\mathbf{M P a}]}\end{array}$ \\
\hline $\begin{array}{l}\text { Aspal BNA } \\
\text { Blend 75/25 }\end{array}$ & \multirow{2}{*}{6,15} & 25 & 5478 \\
\cline { 3 - 4 } $\begin{array}{l}\text { Aspal Shell } \\
70 / 60\end{array}$ & \multirow{2}{*}{6,30} & 45 & 636 \\
\cline { 3 - 4 } & & 25 & 4802 \\
\hline
\end{tabular}

Dari Tabel 2, Tabel 3, dan Tabel 4 dapat dilihat bahwa dengan kadar aspal yang lebih kecil pada BNA Blend 75/25, dapat menghasilkan MQ, IKS, dan MR yang lebih besar daripada aspal PEN 60/70, Hal ini dikarenakan adanya penambahan asbuton pada modifikasi aspal BNA Blend 75/25 sehingga akan meningkatkan kekakuan dari campuran beraspal tersebut [4].

Berdasarkan analisis Marshall dengan metoda kepadatan mutlak dihasilkan KAO pada campuran berasapal BNA Blend 75/25 (6,15\%) yang lebih kecil daripada campuran beraspal PEN 60/70 (6,30\%). Pada kondisi KAO campuran beraspal BNA Blend 75/25 menghasilkan nilai Marshall Quetient (MQ) yang lebih tinggi daripada campuran beraspal PEN 60/70 yaitu $390 \mathrm{~kg} / \mathrm{mm}$ (BNA Blend 75/25) dan 273 $\mathrm{kg} / \mathrm{mm}$ (aspal PEN 60/70).

Hasil uji perendaman Marshall menunjukkan bahwa campuran beraspal BNA Blend 75/25 memiliki ketahanan yang lebih baik terhadap pengaruh air dan suhu tinggi daripada campuran beraspal PEN 60/70. Hal ini ditunjukkan dengan nilai IKS kedua campuran tersebut yaitu masing-masing sebesar $97,60 \%$ dan $95,04 \%$.

Pada temperatur yang sama, nilai modulus Resilien campuran beraspal BNA Blend 75/25 lebih tinggi jika dibandingkan dengan campuran beraspal PEN 60/70, dimana pada temperatur $25^{\circ} \mathrm{C}$, untuk campuran beraspal BNA Blend 75/25 sebesar 5.478 MPa, sedangkan untuk campuran beraspal PEN $60 / 70$ sebesar 4.802 MPa. Hal ini dikarenakan adanya penambahan asbuton pada modifikasi aspal BNA Blend 75/25 sehingga akan meningkatkan nilai modulus Resilien.

\subsection{Hasil Analisis Data Lalu Lintas}

Analisis lalu lintas dilakukan untuk memperoleh besarnya volume dan beban kendaraan rencana di ruas jalan alternatif Nagreg yang dikaji pada tahun pengamatan. Dalam penelitian ini, data volume lalu lintas hasil survey primer selama 1 hari di tahun 2012 diasumsikan sebagai data LHR pada tahun 2012. Berdasarkan data historis volume lalu lintas dan hasil survey primer pencacahan lalu lintas, diperoleh tingkat pertumbuhan setiap kendaraan ruas jalan Cileunyi - Nagreg yaitu 5,74\%.

Dari proyeksi volume lalu lintas, kemudian untuk perhitungan faktor $C E S A$, dilakukan dengan mengkaji Vehicle Damage Factor (VDF) atau Equivalent Standard Axle (ESA) pada kondisi beban izin, CESA ditentukan rumus pada Persamaan 1 berikut [1]:

$$
C E S A=\sum_{\text {Traktor-Trailer }}^{M P} m * 365 * E S A * C * N
$$

dimana: 


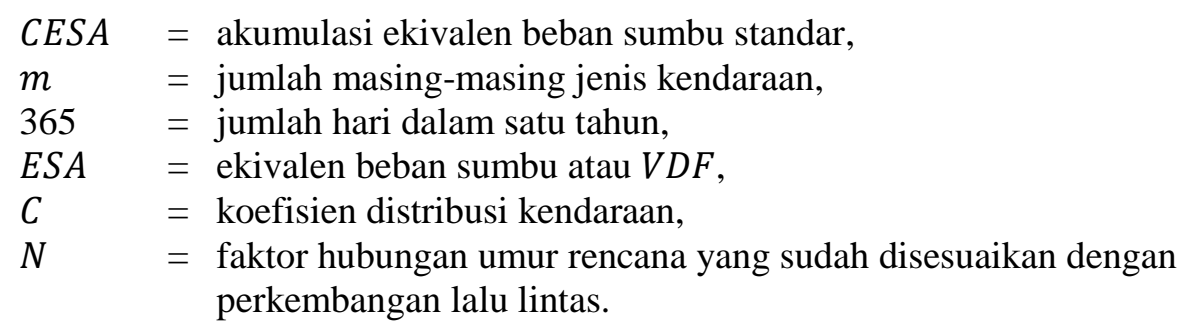

Dari data Design Engineering Design, jalan alternatif Nagreg memiliki lebar 11 meter yang terbagi menjadi 3 lajur 1 arah. Data ini digunakan untuk menganalisis koefisien distribusi pada beban lalu lintas yaitu 0,4 untuk kendaraan ringan (golongan 2-4), sedangkan 0,5 untuk kendaraan berat (golongan 5A7C), sedangkan nilai $N$ telah diperhitungkan dalam proyeksi lalu lintas dengan faktor pertumbuhan 5,74\%. Adapun hasil perhitungan CESA untuk beban normal dapat dilihat pada Tabel 5 [4].

Tabel 5. CESA pada Kondisi Beban Normal Tahun 2012-2021 [4]

\begin{tabular}{cccc}
\hline No & Tahun & Jumlah & CESA \\
\hline 1 & 2012 & 1.333 .533 & $1.333 .533,118$ \\
\hline 2 & 2013 & 1.410 .050 & $2.743 .583,245$ \\
\hline 3 & 2014 & 1.490 .958 & $4.234 .540,863$ \\
\hline 4 & 2015 & 1.576 .508 & $5.811 .048,376$ \\
\hline 5 & 2016 & 1.666 .966 & $7.478 .014,566$ \\
\hline 6 & 2017 & 1.762 .615 & $9.240 .629,874$ \\
\hline 7 & 2018 & 1.863 .753 & $11.104 .382,568$ \\
\hline 8 & 2019 & 1.970 .693 & $13.075 .075,824$ \\
\hline 9 & 2020 & 2.083 .770 & $15.158 .845,804$ \\
\hline 10 & 2021 & 2.203 .335 & $17.362 .180,754$ \\
\hline
\end{tabular}

\subsection{Hasil Analisis Data Environment}

Dengan morfologi wilayah pegunungan dengan rata-rata kemiringan lereng antara 0-8 \%, 8-15\% hingga diatas $45 \%$. Nagreg beriklim tropis yang dipengaruhi oleh iklim muson dengan curah hujan rata-rata antara $1.500 \mathrm{~mm}$ sampai dengan $4.000 \mathrm{~mm}$ per tahun. Suhu udara berkisar antara $12^{\circ} \mathrm{C}$. sampai $29^{\circ} \mathrm{C}$ dengan kelembaban antara $78 \%$ pada musim hujan dan $70 \%$ pada musim kemarau. Hasil survey primer suhu temperatur permukaan jalan di lapangan adalah sebesar $45^{\circ} \mathrm{C}$. Untuk geometrik jalan alternatif Nagreg memiliki kelandaian 2-11\%.

Dari data Design Engineering Design, jalan alternatif Nagreg merupakan jalan nasional yang memiliki kelandaian yang bervariatif, ditambah curah hujan yang tinggi sebesar 3.848,8 $\mathrm{mm} /$ tahun, dan faktor kendaraan berat sebesar 21,66\% maka dapat diperoleh Faktor Regional $(F R)$ seperti tertera pada Tabel 6 dan didapat nilai $F R$ rata-rata $1,76$.

\subsection{Hasil Analisis Stuktur Perkerasan}

Berdasarkan data sekunder hasil pengujian test coredrill pada tahun 2011 didapat data tebal perkerasan pada jalur alternatif Nagreg dari KM 0+000 s/d KM 4+600 meliputi jenis material yang memiliki ACWC dengan menggunakan aspal BNA Blend 75/25 dan tebal di setiap lapisan perkerasan jalan. Data tebal perkerasan pada 3 (tiga) lajur yang ada memiliki ketebalan yang relatif sama untuk tiap lajurnya seperti yang terlihat pada Gambar 2. 


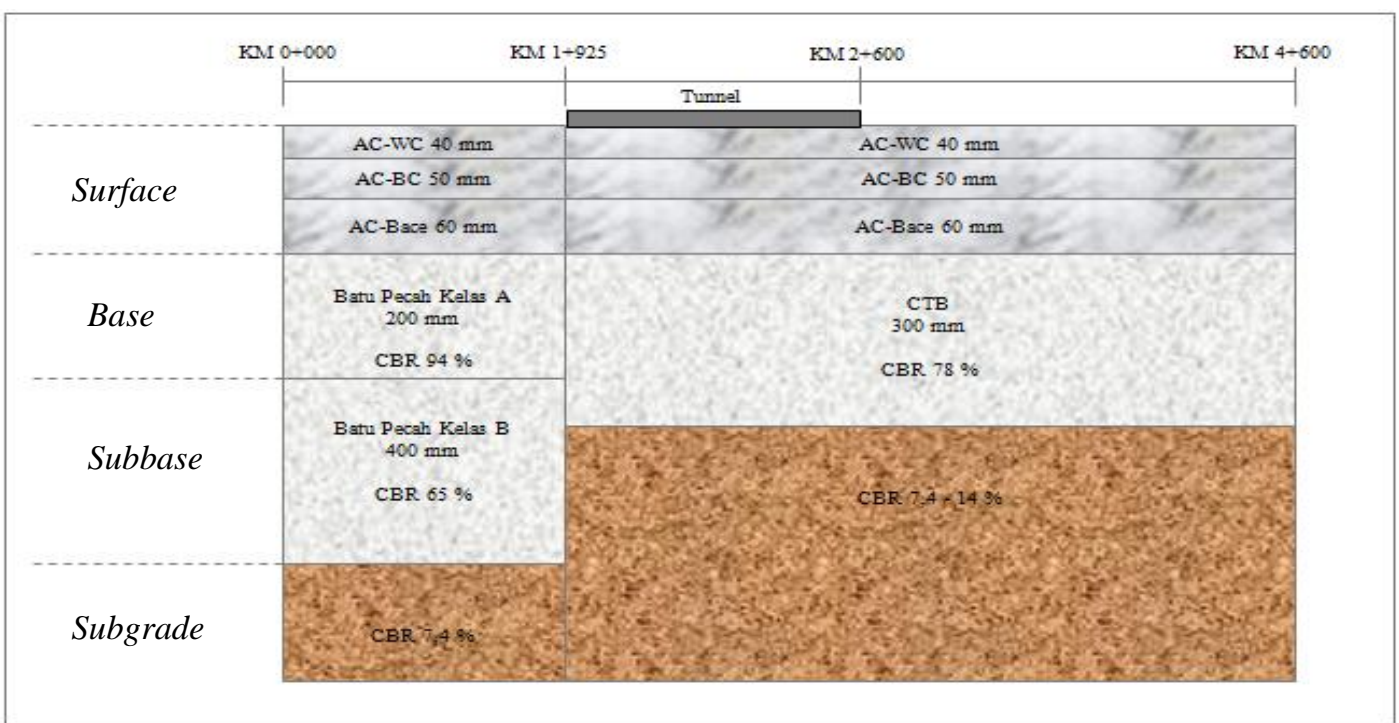

Gambar 2. Tebal perkerasan jalan alternatif Nagreg (STA 0+000 - STA 4+600)

Untuk analisis struktur lapisan perkerasan digunakan nilai Indeks Tebal Perkerasan (ITP), yang terdiri dari fungsi tebal perkerasan $(t)$ dan koefisien kekuatan relatif setiap lapisan perkerasan $(a)$. Nilai yang berbeda dalam penelitian ini terdapat pada nilai $a_{1}$, dimana jenis campuran beraspal pada lapisan aus (AC-WC) yang digunakan berbeda, yaitu BNA Blend 75/25 dan PEN 60/70. Hubungan nilai nilai $a_{1}$ dan modulus Resilien campuran $\left(M_{R}\right)$ yang dalam AASHTO direlasikan pada Persamaan (2) adalah sebagai berikut [1]:

$$
a_{1} \approx 0,37964 \log \left(M_{R \cdot 20^{\circ} \mathrm{C}}\right)-0,89304
$$

dimana:

$M_{R .20^{\circ} \mathrm{C}}=$ modulus Resilien pada suhu $20^{\circ} \mathrm{C}(\mathrm{MPa})$.

Dari Persamaan (2) tersebut dan hasil uji lanjut UMATTA maka akan diketahui nilai koefisien kekuatan relatif $\left(a_{1}\right)$ dari modulus Resilien setiap jenis campuran, yaitu campuran beraspal BNA Blend $75 / 25$ sebesar $6.883 \mathrm{MPa}$ memiliki nilai $a_{1} 0,56$, sedangkan campuran beraspal PEN 60/70 sebesar 5.873 MPa memiliki nilai $a_{1}$ 0,54; sehingga perkerasan jalan yang menggunakan BNA Blend 75/25 menghasilkan nilai $a$ 3,7 \% lebih besar dibandingkan dengan aspal Pen 60/70.

Pada tebal dan koefisien kekuatan relatif yang sama disetiap lapisan perkerasan jalan, kecuali untuk lapisan AC-WC, nilai ITP atau nilai struktural perkerasan jalan yang menggunakan BNA Blend 75/25 memiliki nilai yang lebih tinggi dibandingkan perkerasan jalan yang menggunakan aspal PEN 60/70, yaitu 17,8 dan 17,7. Perbedaan ini tidak terlalu signifikan dikarenakan AC-WC merupakan lapisan aus yang memiliki pengaruh kecil terhadap struktural perkerasan jalan

\subsection{Analisis Umur Rencana Perkerasan Jalan}

Umur rencana (masa pelayanan) jalan alternatif Nagreg yang dianalisis sangat dipengaruhi oleh hasil penurunan ITP dan bertambahnya beban berulang kendaraan (CESA). Semakin menurunnya nilai ITP dan meningkatnya volume kendaraan maka akan menurunkan nilai $I P_{a k h i r}$ di tahun berikutnya, sehingga dari grafik penurunan masa pelayanan jalan dapat diketahui kapan jalan tersebut akan kritis atau habis masa umur jalan. Menurut Ditjen Bina Marga, prinsip dasar penurunan kinerja pelayanan jalan selama umur rencana dilihat dari nilai ITP dan IP pada kurva deterioration (lihat Gambar 3) dan menggunakan persamaan dasar yang digunakan oleh Metode Analisa Komponen, dapat dilihat pada Persamaan 3) [2]. 


$$
\log \left(W_{t 18}\right)=9,36 \log \left(\frac{I T P}{2,54}+1\right)-0,20+\frac{\log \frac{\left(I P_{\text {awal }}-I P_{\text {akhir }}\right)}{4,2-1,5}}{0,40+\frac{1.904}{\left(\frac{I T P}{2,54}+1\right)^{5,19}}}+\log \left(\frac{1}{F R}\right)+0,372(D D T-3)
$$

dimana:

$W_{t 18}=$ Cumulative number of Standard axles over a design life,

ITP $=$ Indeks Tebal Perkerasan,

$I P_{\text {awal }}=$ Indeks Permukaan Awal,

$I P_{\text {akhir }}=$ Indeks Permukaan Akhir,

$F R \quad=$ Faktor Regional,

DDT = Daya Dukung Tanah.

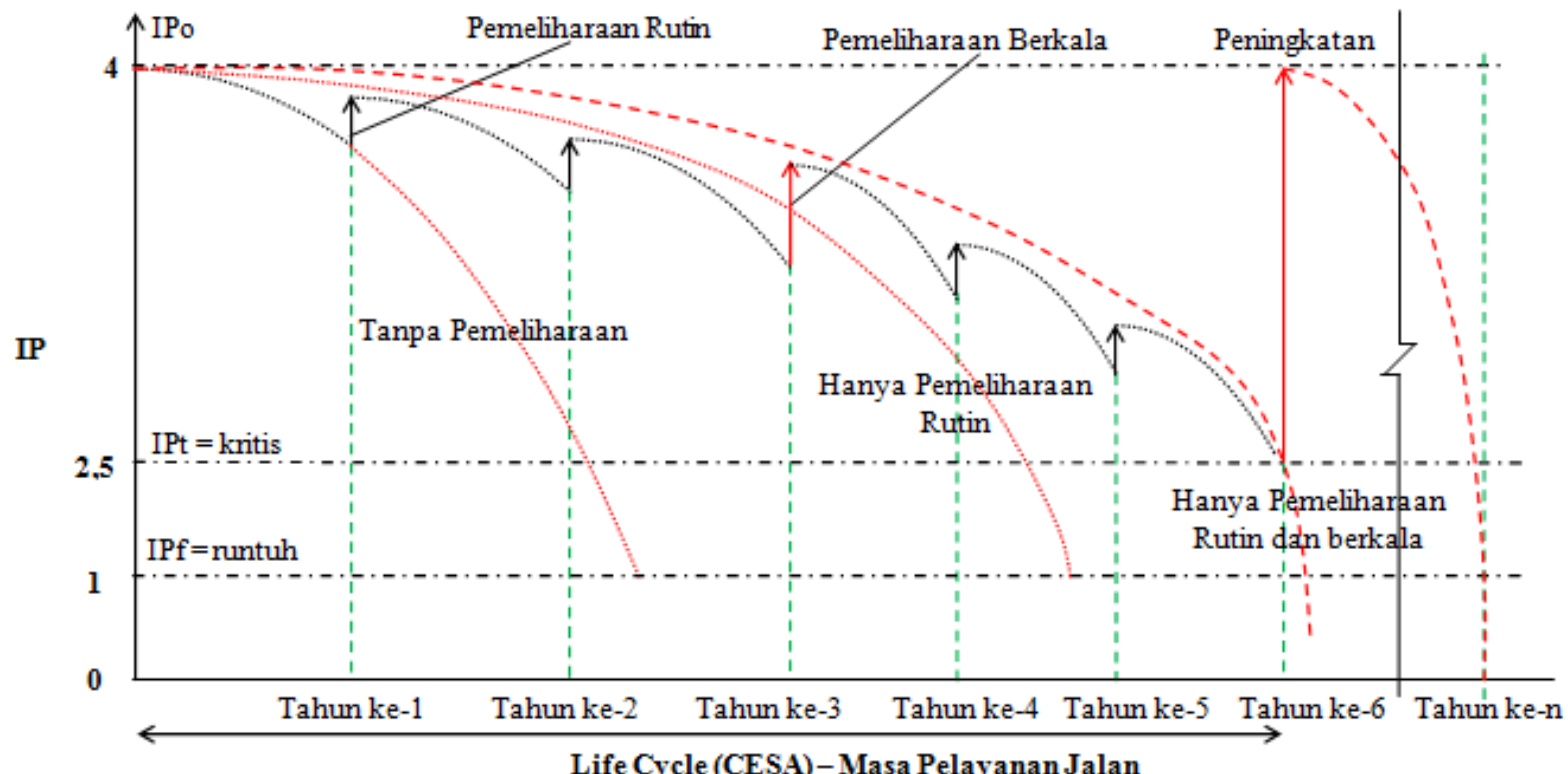

Gambar 3. Pavement Deterioration Model [3]

Umur rencana pada perkerasan jalan ini memiliki waktu masa pelayanan hingga Indeks Permukaan (IP) kritis yaitu 2,5. Dengan demikian maka harus diadakan pemeliharaan terhadap perkerasan jalan tersebut. Dalam penelitian ini, dapat dilihat masa pelayanan (umur rencana) akibat adanya pengaruh jenis pemeliharaan. Pada pemeliharaan rutin dan berkala dilakukan dapat dilihat pada Gambar 4 di bawah ini. 


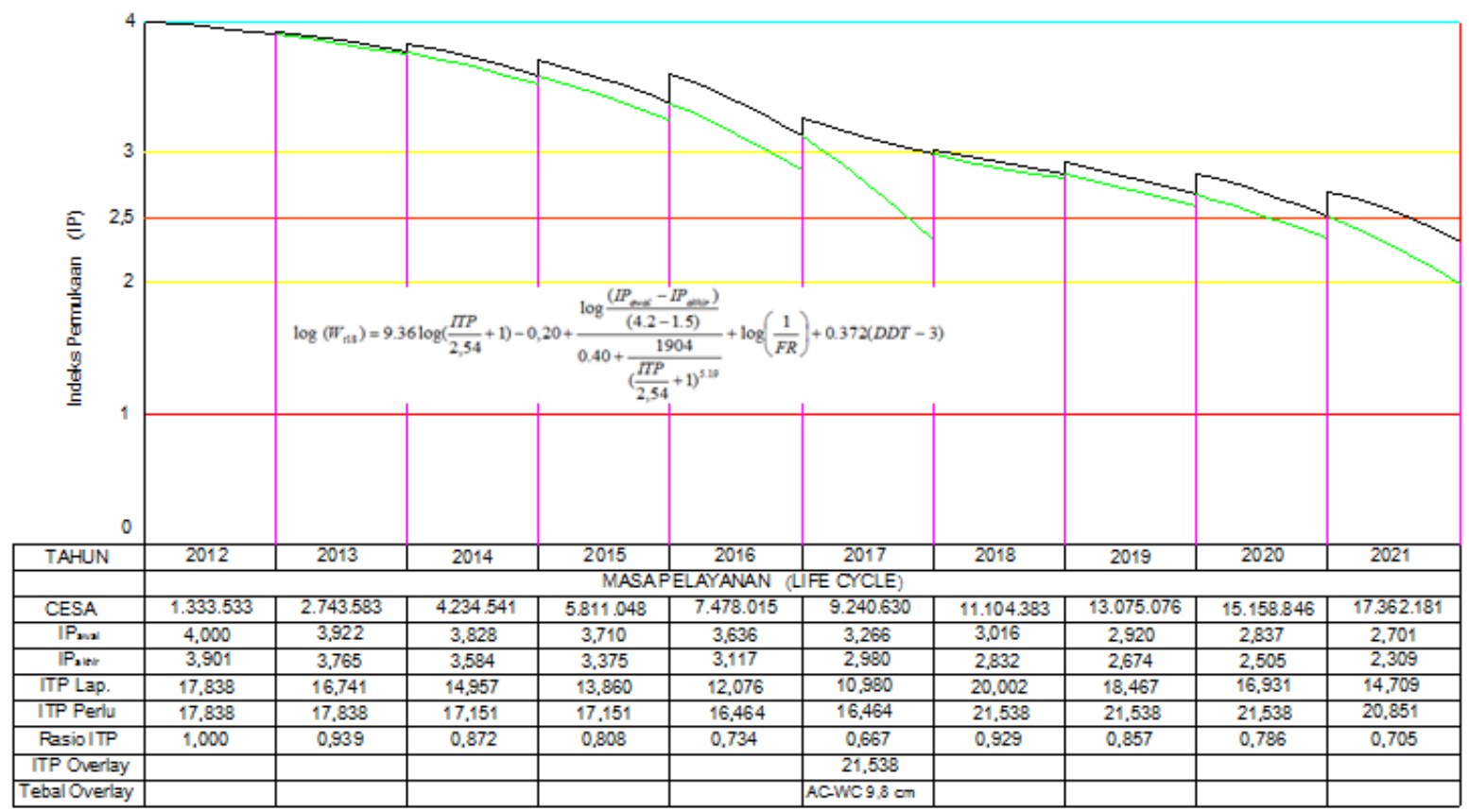

Gambar 4. Kurva deterioration perkerasan jalan yang menggunakan BNA Blend 75/25 dengan pemeliharan rutin dan berkala

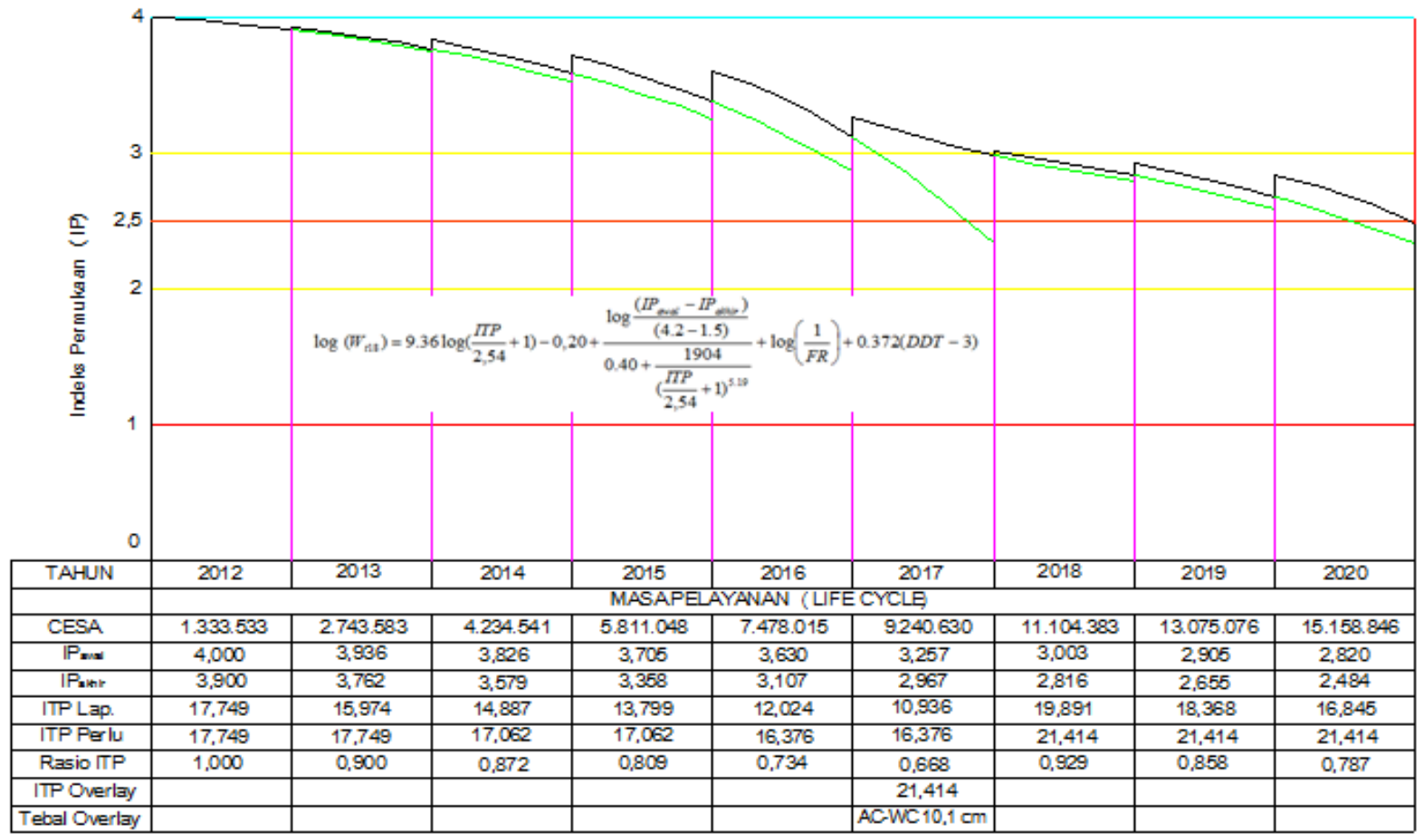

Gambar 5. Kurva deterioration perkerasan jalan yang menggunakan Aspal PEN 60/70 dengan pemeliharan rutin dan berkala

Dari Gambar 4 dan Gambar 5 di atas dapat dilihat bahwa pada pemeliharaan rutin dan berkala yang menggunakan BNA Blend 75/25 memiliki Umur Rencana lebih lama daripada aspal PEN 60/70, yaitu 10 tahun untuk BNA Blend 75/25 dan 9 tahun untuk aspal PEN 60/70, sehingga perkerasan jalan yang menggunakan BNA Blend 75/25 menghasilkan Umur Rencana 1 tahun lebih lama dibandingkan dengan aspal Pen 60/70. 
Hal ini dikarenakan pada tahun 2020 perkerasan jalan yang menggunakan aspal PEN 60/70 telah mencapai nilai $I P_{t}$, yaitu 2,484, sedangkan perkerasan jalan yang menggunakan BNA Blend 75/25 memiliki nilai $I P_{t}$ masih 2,505 .

\section{SIMPULAN}

Berdasarkan analisis data hasil pengujian diperoleh bahwa:

1. Pengujian sifat fisik kedua jenis aspal menunjukkan bahwa BNA Blend 75/25 lebih keras daripada aspal Shell 60/70, sehingga BNA Blend 75/25 membutuhkan suhu yang lebih tinggi daripada aspal Shell 60/70 baik untuk suhu pencampuran maupun suhu pemadatan dan membutuhkan biaya lebih tinggi.

2. Berdasarkan analisis Marshall dengan metode kepadatan mutlak dihasilkan KAO pada campuran berasapal BNA Blend 75/25 yang lebih kecil daripada campuran beraspal Shell 60/70. Dan pada kondisi KAO campuran beraspal BNA Blend 75/25 menghasilkan nilai MQ, IKS, dan modulus Resilien yang lebih tinggi daripada campuran beraspal Shell 60/70.

3. Dari hasil modulus Resilien yang dilakukan di laboratorium, dapat disimpulkan bahwa koefisien kekuatan relatif lapisan AC-WC yang menggunakan BNA Blend 75/25 memiliki nilai yang lebih tinggi daripada aspal Shell 60/70, yaitu 0,56 dan 0,54, sehingga perkerasan jalan yang menggunakan BNA Blend 75/25 menghasilkan nilai a 3,7 \% lebih besar dibandingkan dengan aspal Pen 60/70.

4. Berdasarkan kondisi beban normal dan penurunan kondisi struktural selama Umur Rencana $\left(I P_{t}=\right.$ 2,5) didapat bahwa Umur Rencana yang menggunakan BNA Blend 75/25 adalah 10 tahun, sedangkan Umur Rencana yang menggunakan aspal PEN 60/70 adalah 9 tahun, sehingga perkerasan jalan yang menggunakan BNA Blend 75/25 menghasilkan Umur Rencana 1 tahun lebih lama dibandingkan dengan aspal Pen 60/70.

\section{DAFTAR PUSTAKA}

[1] AASHTO. Standard Spesifications for Transportation Materials and Methods of Sampling and Testing. Washington D.C.; 1993.

[2] Kementerian Pekerjaan Umum. Metoda Analisa Komponen Perencanaan Tebal Perkerasan. Direktorat Jenderal Bina Marga; 1989.

[3] Kementerian Pekerjaan Umum. Seksi 6.3 Spesifikasi Campuran Beraspal Panas. Direktorat Jenderal Bina Marga; 2010.

[4] Widianto, B. K. (2012). Kajian Umur Rencana Cost Terhadap Perkerasan Jalan Campuran Lapis Aus (AC-WC) Yang Menggunakan BNA Blend 75/25. (Studi Kasus: Jalan Alternatif Nagreg), Tesis. Bandung: Institut Teknologi Bandung; 2012. 